\title{
Turning gelidium amansii residue into nitrogen-doped carbon nanofiber aerogel for enhanced multiple energy storage
}

Daohao $\mathrm{Li}^{\mathrm{a}}$, Yu Wang ${ }^{\mathrm{a}}$, Yuanyuan Sun ${ }^{\mathrm{a}}$, Yun Lu ${ }^{\mathrm{b}}$, Shuai Chen ${ }^{\mathrm{c}}$, Bingbing Wang ${ }^{\mathrm{a}}$, Huawei Zhang ${ }^{\mathrm{d}}$, Yanzhi Xia ${ }^{* a}$, Dongjiang Yang ${ }^{* a, e}$

${ }^{a}$ Collaborative Innovation Center for Marine Biomass Fibers, Materials and Textiles of Shandong Province, Institute of Marine Biobased Materials, School of Environmental Science and Engineering, Qingdao University, Qingdao 266071, P. R. China.

${ }^{\mathrm{b}}$ Department of Wood Anatomy and Utilization, Research Institute of Wood Industry, Chinese Academy of Forestry, Beijing 100091, P. R. China.

${ }^{\mathrm{c}}$ State Key Laboratory of Coal Conversion, Institute of Coal Chemistry, Chinese Academy of Science, Taiyuan 030001, P. R. China.

${ }^{\mathrm{d} C o l l e g e}$ of Chemical and Environmental Engineering, Shandong University of Science and Technology, Qingdao 266590, P. R. China.

${ }^{\mathrm{e}}$ Queensland Micro- and Nanotechnology Centre (QMNC), Griffith University, Nathan, Brisbane, Queensland 4111, Australia.

Corresponding authors: E-mail: d.yang@qdu.edu.cn (D. Yang); xiayz@qdu.edu.cn (Y. Xia) 
GRAPHICAL ABSTRACT

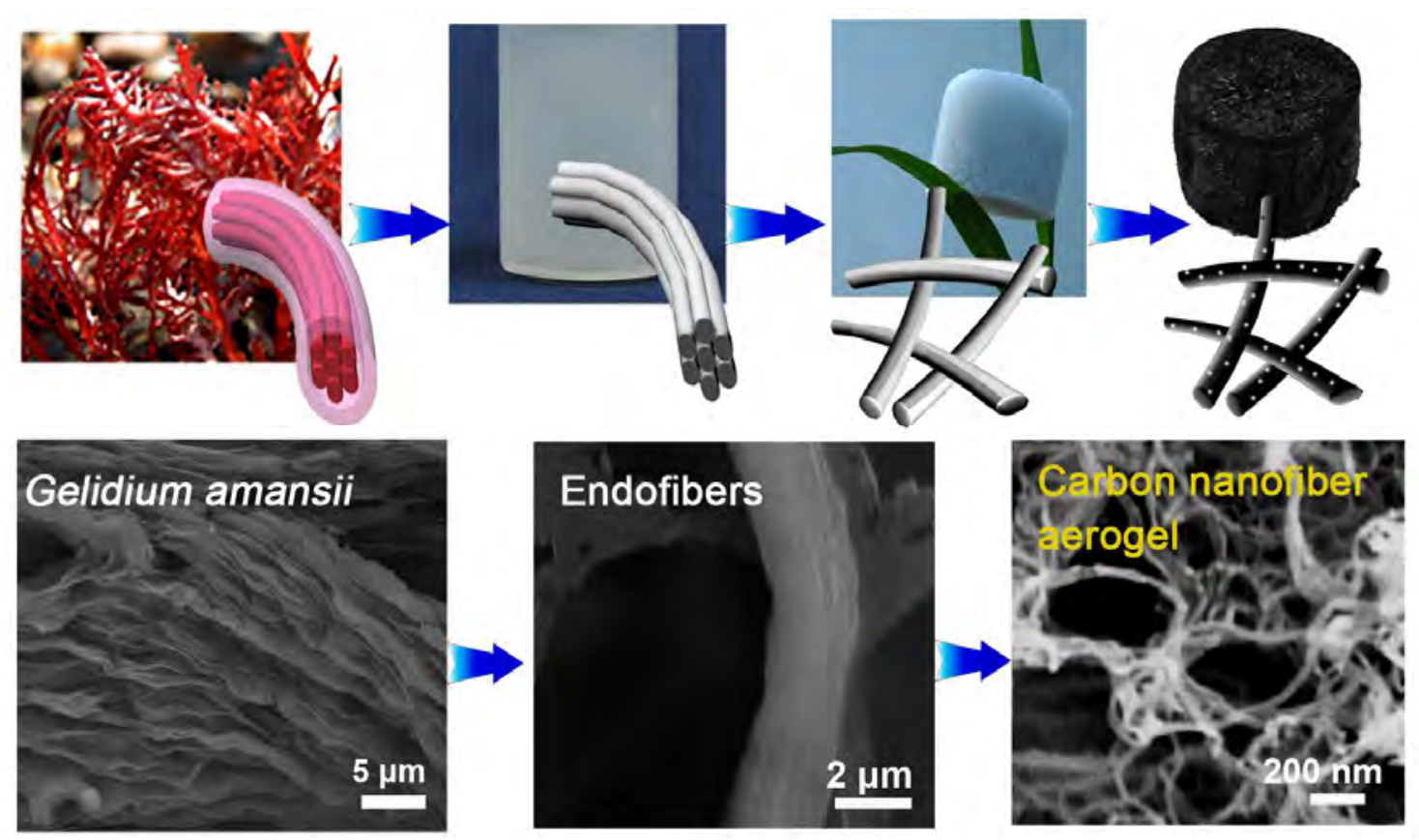




\section{Abstract}

Three-dimensional (3D) carbonaceous aerogels assembled by one-dimensional (1D) carbon nanofibers (CNF) have attracted much attention, bacause their unique interconnected and hierarchical porous structure can offer a wide range of applications in environmental remediation and energy storage. Herein, the residue of gelidium amansii (mainly endofibers, $\sim 1.6 \mu \mathrm{m}$ ) after extraction of agar were used as precursor to fabricate nanofibrilated cellulose by using facile ultrosonication treatment. The nanofibrilated celluloses are highly engineered nanofibers with average diameter of $\sim$ $90 \mathrm{~nm}$. Then the 1D cellulose nanofibers could be assembled into 3D nanofiber aerogels after freeze drying. The subsequent pyrolysis in $\mathrm{NH}_{3}$ and activition could result in the formation of $\mathrm{N}$-doped $\mathrm{CNF}$ areogel (N-PCNFA), where the oxygen-containing groups in cellulose macromolecules converted to $\mathrm{H}_{2} \mathrm{O}, \mathrm{CO}$, and $\mathrm{CO}_{2}$. The N-PCNFA with hierarchically porous structure, high surface area $\left(2290 \mathrm{~m}^{2} \mathrm{~g}^{-1}\right)$, N-doping, and 3D interconnected channels are benificial to electrolyte ions and electron transportation. The N-PCNFA displayed high capacity and long-term stability as energy storage material. This work highlights a new strategy in highly efficient utilizing the marine biomass waste for developing low-cost and functional carbon aerogel for multiple energy storage. 
Carbon nanomaterials, including carbon nanotube, carbon nanosphere, graphene, and carbon nanofiber (CNF) etc, have been considered as the promising energy storage materials for lithium ion batteries (LIBs) and supercapacitors (SCs), due to their relatively high electronic conductivity, high specific capacity, accessibility, and excellent stability [1-3]. Particularly, one-dimensional (1D) CNF has been extensively explored for energy storage because of its oriented electronic/ionic transport pathway, excellent mechanical property, and high surface to volume ratio [4, 5]. However, the ordinary CNF usually cannot meet the increasing requirement for excellent performance energy storage devices due to its dissatisfactory electrolyte ions and electron transports. Constructing porous structure in CNF with high surface area offer sufficient porous channels and large interface between active sites and electrolyte for promoting the electrolyte ion diffusion, which can achieve the high requirement of energy storage devices [6-9]. Recently, three-dimensional (3D) carbonaceous aerogels assembled by $1 \mathrm{D}$ porous $\mathrm{CNF}$ have been attracted much attention. The adequate space of hierarchically 3D interconnected CNF-based framework and high length-diameter ratio of $1 \mathrm{D} \mathrm{CNF}$ could synergistically promote electrolyte ions diffusion and electron transpot, further enhancing the energy storage performance.

Generally, the fabrication of such 3D hierarchical porous CNF depends on the pyrolysis of polymer (such as poly(vinyl alcohol), polyacrylonitrile, and polyimide) nanofiber through simple electrospinning synthetics, generating continuous nanofibers with controlled size $[10,11]$. The non-renewable polymer precursors and toxic byproducts hinder the sustainable applications of such CNF. Thus, low-cost, sustainable, and large-scale production of $3 \mathrm{D}$ porous $\mathrm{CNF}$ with cheap and renewable precursors is still a vital research demand. Nowadays, many valuable CNF derived from sustainable 
biomass have been developed through innovative strategies, which show great potential in energy storage [12-15]. For example, bacterial cellulose is a promising candidate for the fabricating of CNF, opening a green and sustainable biomass-converting method. Lu et al. controllably synthesized a series of 3D porous CNF aerogel with different dimeters using earth-abundant bamboo as precursors [12]. With the fast exploration of ocean, the abundant algae resources, mainly including browm, red, and green algas, have been extensively concerned [16-25]. Similar to bamboo, some of abundant seaweed $(\sim 30,000,000$ tons per year) contain high cellulose, making them possible to produce CNF aerogel via a sustainable route. For instance, Gelidium amansii (GA), one of the most abundant red algae species, mainly is composed of mucilaginous materials and endofibers. After the extraction of agar or carrageenan from polysaccharide complexes of the mucilaginous materials, the remaining solid endofibers are cellulose $(8 \%-11 \%)[26,27]$. However, the GA residue shows low value for further utilization at present.

Herein, we used such GA residue (mainly endofibers, $\sim 1.6 \mu \mathrm{m}$ ) as precursor to fabricate nanofibrilated cellulose by using facile ultrosonication treatment, since the ultrosonication process could break the weak macromolecular interfibrillar hydrogen bonding and Wander Waals force. The nanofibrilated celluloses are highly engineered nanofibers with average diameter of $\sim 90 \mathrm{~nm}$. Then the 1D cellulose nanofibers could be assembled into 3D nanofiber aerogels after freeze drying. The subsequent pyrolysis in $\mathrm{NH}_{3}$ and activition could result in the formation of $\mathrm{N}$-doped CNF areogel (N-PCNFA). When used as energy storage material, the important characteristics of N-PCNFA, such as 3D interconnected network, high surface area $\left(2290 \mathrm{~m}^{2} \mathrm{~g}^{-1}\right)$, porous structure and $\mathrm{N}$ doping, not only increase the contact surface area of active material and electrolyte to 
decrease ion diffusion distance, but also enhance the conductivity of electrode material. For instance, as lithium storage material, N-PCNFA exhibits a high specific capacity and good cycling stability (572 $\mathrm{mAh} \mathrm{g}^{-1}$ at $1 \mathrm{~A} \mathrm{~g}^{-1}$ after 600 cycles), and excellent rate performance (220 $\mathrm{mAh} \mathrm{g}^{-1}$ at high current density of $10 \mathrm{~A} \mathrm{~g}^{-1}$ ). It also displays the excellent capacitive behavior (in a three-electrode system, 320 and $248 \mathrm{~F} \mathrm{~g}^{-1}$ at 1 and $100 \mathrm{~A} \mathrm{~g}^{-1}$, respectively) for SCs.

\section{Experimental Section}

\subsection{Materials preparation}

The GA was firstly decolorized by $\mathrm{NaClO}_{2}$ solution to produce bleached GA pulp, and washed with $\mathrm{H}_{2} \mathrm{O}$ to $\mathrm{pH}=7$. Then, the obtained sample was treated with $1 \mathrm{M} \mathrm{KOH}$ solution at $85^{\circ} \mathrm{C}$ for $2 \mathrm{~h}$, which has a significant and positive effect on solubilizing the agar from the GA. After filtration, the filtered residue was endofiber (mainly cellulose). To fabricate cellulose nanofiber, the typically ultrasound method was used. The residue was put in a beaker with water, and then the pulsed high-intensity $(60 \mathrm{KHz}, 300 \mathrm{~W})$ ultrasonication was performed with the water/ice bath for 30 min (setting $50 \%$ duty cycle for reducing temperature variation). The nanofibrillated cellulose was obtained, and the cellulose nanofiber/water dispersion was frozen to $-70{ }^{\circ} \mathrm{C}$. The freeze-drying was used to dry it to get the cellulose nanofiber aerogel. Then, the cellulose nanofiber aerogel was pyrolyzed at $700{ }^{\circ} \mathrm{C}$ for $1 \mathrm{~h}$ under the ammonia or nitrogen atmosphere (heating rate: $2{ }^{\circ} \mathrm{C} \mathrm{min}^{-1}$ ) to fabricate the $\mathrm{N}$-doped carbon nanofiber aerogel (N-CNFA) and carbon nanofiber aerogel (CNFA), respectively. The N-CNFA and CNFA were activated by $\mathrm{KOH}$ at $800{ }^{\circ} \mathrm{C}$ for $1 \mathrm{~h}$ (weight ratio of $\mathrm{KOH} /$ samples $=4 / 1$ ) under nitrogen atmosphere and then washed with $1 \mathrm{M} \mathrm{HCl}$ and deionized water until $\mathrm{pH}=7$ to obtain the N-PCNFA and PCNFA, respectively. 


\subsection{Characterization.}

Scanning electron microscopy (SEM) images were obtained using a JSM-7001F instrument. Transmission electron microscopy images (TEM) were obtained using a JEM-2100F electron microscope with an accelerating voltage of $200 \mathrm{kV}$. Coupled thermogravimetric analysis and mass spectrum were obtained using Evolution 16/18 and OMNI star instruments. The crystal structures of samples were characterized by Xray diffraction (XRD, DX2700, China). Raman spectroscopy (Renishaw 1000NR) was performed at room temperature on a Renishaw 1000 Raman spectrometer using an Ar ion laser at $514.5 \mathrm{~nm}$ excitation line. The specific surface area was calculated by the Brunauer-Emmett-Teller (BET) method from data in a relative pressure $\left(\mathrm{P} / \mathrm{P}_{0}\right)$ range between 0.001 and 0.25 and pore size distribution plots were derived from the adsorption branch of the isotherms based on the BJH model. The chemical composition was investigated by X-ray photoelectron spectroscopy (XPS) using an ESCALab250 electron spectrometer (Thermo Scientific Corporation) with monochromatic $150 \mathrm{~W} \mathrm{Al}$ $\mathrm{K} \alpha$ radiation.

\subsection{Electrochemical measurements.}

The obtain samples were mixed with poly (vinylidene fluoride) (PVDF) and acetylene black at a weight ratio of 8:1:1 using the N-methyl-2-pyrrolidone (NMP) as solution. Then, the resultant slurry was uniformly pasted on $\mathrm{Cu}$ foil and dried in a vacuum oven at $120{ }^{\circ} \mathrm{C}$ for $10 \mathrm{~h}$. The electrolyte was the solution of $1 \mathrm{M} \mathrm{LiPF}_{6}$ in ethylene carbonate (EC)/dimethyl carbonate (DMC)/diethyl carbonate (DEC) (1:1:1, in wt\%). CR2016-type coin cells were assembled in a glove box using Li metal foil as both the counter and reference electrodes. Cyclic voltammetry (CV) was performed using on a CHI 760 E electrochemical workstation ( $\mathrm{CH}$ Instruments, Inc.). The 
galvanostatic charge/discharge (GCD) tests were conducted using a cell testing instrument (LAND CT2001A).

The samples were tested on three-electrode system and two-electrode system with $6 \mathrm{M} \mathrm{KOH}$ as the electrolyte for SCs. In a three-electrode measurement system, Pt wire, $\mathrm{Ag} / \mathrm{AgCl}$, and $\mathrm{Ni}$ foam were used as the counter, reference electrodes, and current collector, respectively. For the two-electrode cells, the electrodes were prepared by mixing $85 \mathrm{wt} \%$ active materials, $10 \mathrm{wt} \%$ carbon black, and $5 \mathrm{wt} \%$ poly-(vinylidene fluoride). The loading density of the electrode is about $2 \mathrm{mg} \mathrm{cm}^{-2}$. The $\mathrm{CV}, \mathrm{GCD}$, and electrochemical impedance spectrum (EIS) test were performed using the CHI 760E electrochemical workstation. For quantitative considerations, the specific capacitances of the samples were calculated from the GCD values tested on three-electrode system according to the formula (1) and two-electrode system according to the formula (2):

$$
\begin{gathered}
\mathrm{C}=\frac{I \times \Delta t}{m \times \Delta V} \\
\mathrm{C}=\frac{2 I \times \Delta t}{m \times \Delta V}
\end{gathered}
$$

where $\mathrm{C}\left(\mathrm{F} \mathrm{g}^{-1}\right)$ is the specific capacitance, I (A) is the discharge current, $\Delta \mathrm{t}(\mathrm{s})$ is the discharge time, $\mathrm{m}(\mathrm{g})$ is the total mass of the one electrode material, and $\Delta \mathrm{V}(\mathrm{V})$ is the potential window.

\section{Results and discussion}

\subsection{Characterization of N-PCNFA}




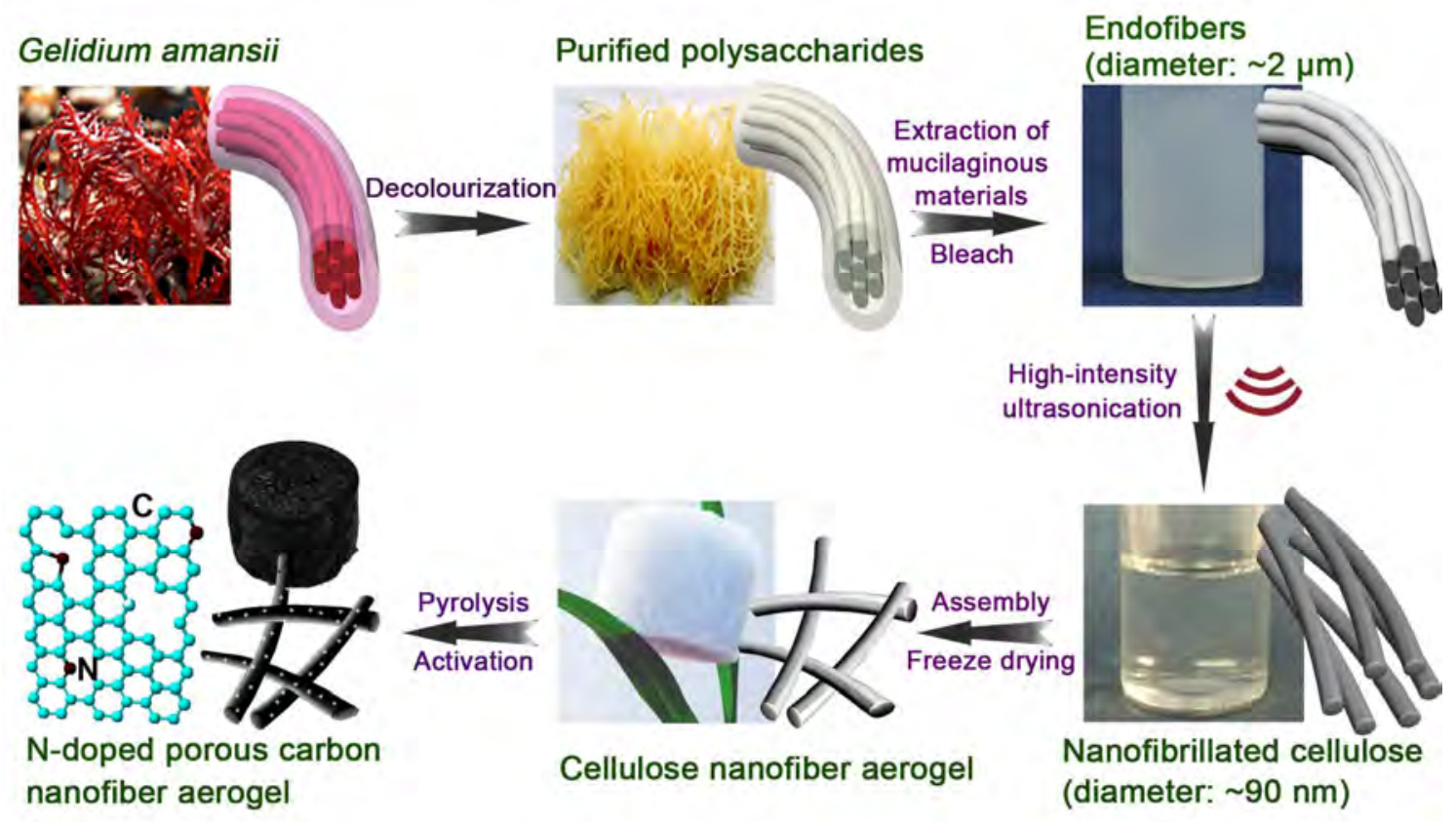

Fig. 1. Schematic illustration on the synthesis process of N-PCNFA.

The preparation process of N-PCNFA is illustrated in Fig. 1. The GA were collected from Qingdao coastal waters. In the first step, the GA was chemical purified like decolorization and dimineralization to remove impurities like mud, dirt, surface attached substances, and the red colour to obtain purified GA. Then, the wetted bleached endofiber with average diameter of $\sim 1.6 \mu \mathrm{m}$ can be obtained from extracting the agar from GA through the processes of bleaching, dissolution, and filtration. In this process, agar, sugar, and starch were removed, and the algal cellulose were retained. Given that ultrasonic cavitation can break the macromolecular interfibrillar hydrogen bonding and the Wander Waals force $[28,29]$, ultrasonication treatment could gradually disassemble the micro-scale endofibers into nanofibers. The cellulose nanofibers with average diameter of $\sim 90 \mathrm{~nm}$ were obtained after ultrasonication treatment $(60 \mathrm{KHz}, 300 \mathrm{~W})$ of 30 min during which the endofiber/water suspention converts to clear solution. Then after tert-butyl alcohol freeze-drying, the 1D cellulose nanofiber building blocks assembled into 3D aerogel. To fabricate highly porous $\mathrm{N}$-doped carbon nanofiber 
aerogel (N-PCNFA), the cellulose nanofiber aerogel was pyrolyzed $\left(700{ }^{\circ} \mathrm{C}\right)$ in the presence of $\mathrm{NH}_{3}$ atmosphere and then was activated by using potassium hydroxide activation $\left(800^{\circ} \mathrm{C}\right)$ for $1 \mathrm{~h}$.
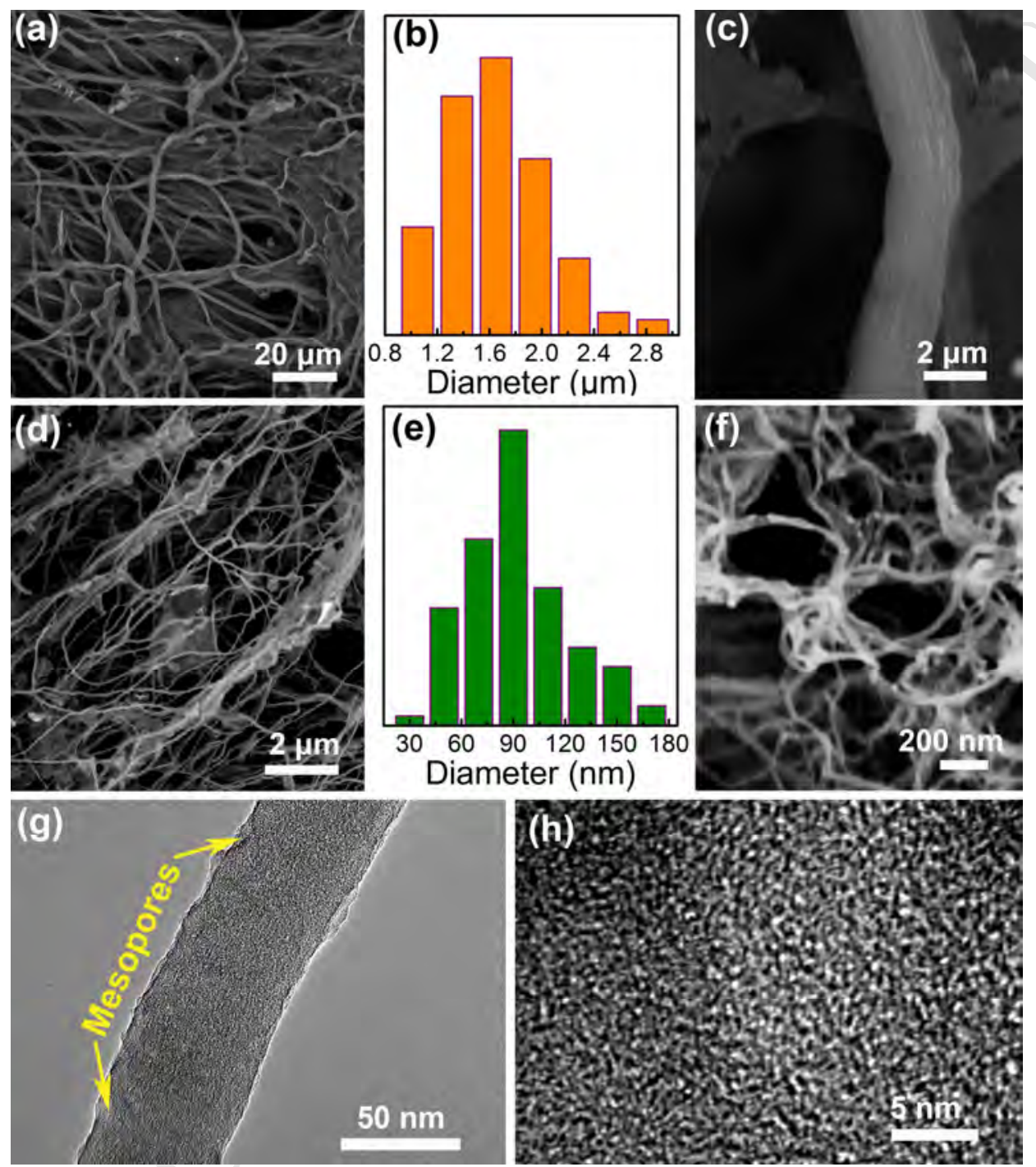

Fig. 2. SEM images of $(a, c)$ the fibrous cellulose, (d) the cellulose nanofiber aerogel, and (f) N-PCNFA. The diameter distributions of (b) the fibrous cellulose, and (e) the cellulose nanofiber aerogel. (g) TEM and (h) HRTEM images of NPCNFA.

The morphologies of the prepared cellulose endofiber, cellulose nanofiber aerogel, and N-PCNFA were determined by scanning electron microscopy 
(SEM). The crumpled GA contains bundled and stacked firous cellulose (Fig. S1). In the agar extraction process, the cytoderm of GA is destroyed by chemicals and the GA residue is fibrous cellulose with obvious fibrous morphology (Fig. 2a). The average diameter of the endofibers is $\sim 1.6 \mu \mathrm{m}$ (Fig. 2b). Such endofibers also exhibit crumpled surface (Fig. 2c). Fig. 2d shows the morphology of cellulose nanofiber aerogel after ultrasonication treatment, producing slender cellulose nanofibers with average diameter of $\sim 90 \mathrm{~nm}$ (Fig. 2e). After pyrolysis in $\mathrm{NH}_{3}$ atmosphere and $\mathrm{KOH}$ activation, the N-PCNFA sample was obtained. X-ray diffraction (XRD) pattern of N-PCNFA shows broad diffraction peaks located at about $25^{\circ}$, which corresponds to amorphous carbon structure (Fig. S2). Its aerogel morphology inherits from the celloluse nanofiber aerogel (Fig. 2f). However, the average diameter of the carbon nanofibers reduces to $\sim 50 \mathrm{~nm}$, only half of that of the cellulose nanofibers due to the decomposition of cellulose. The transmission electron microscopy (TEM) was used to characterize microstructure of the N-PCNFA. As shown in Fig. $2 \mathrm{~g}$, the small-sized mesopores $(<10 \mathrm{~nm})$ are observed in a single carbon nanofiber. This mesoporous structure can offer an avail the electrolyte storage to shorten the electrolyte ions diffusion distance, enhancing the electrochemical performance [30]. The high resolution TEM (HRTEM) image illustrates that the N-PCNFA shows amorphous carbon structure (Fig. 2h). 

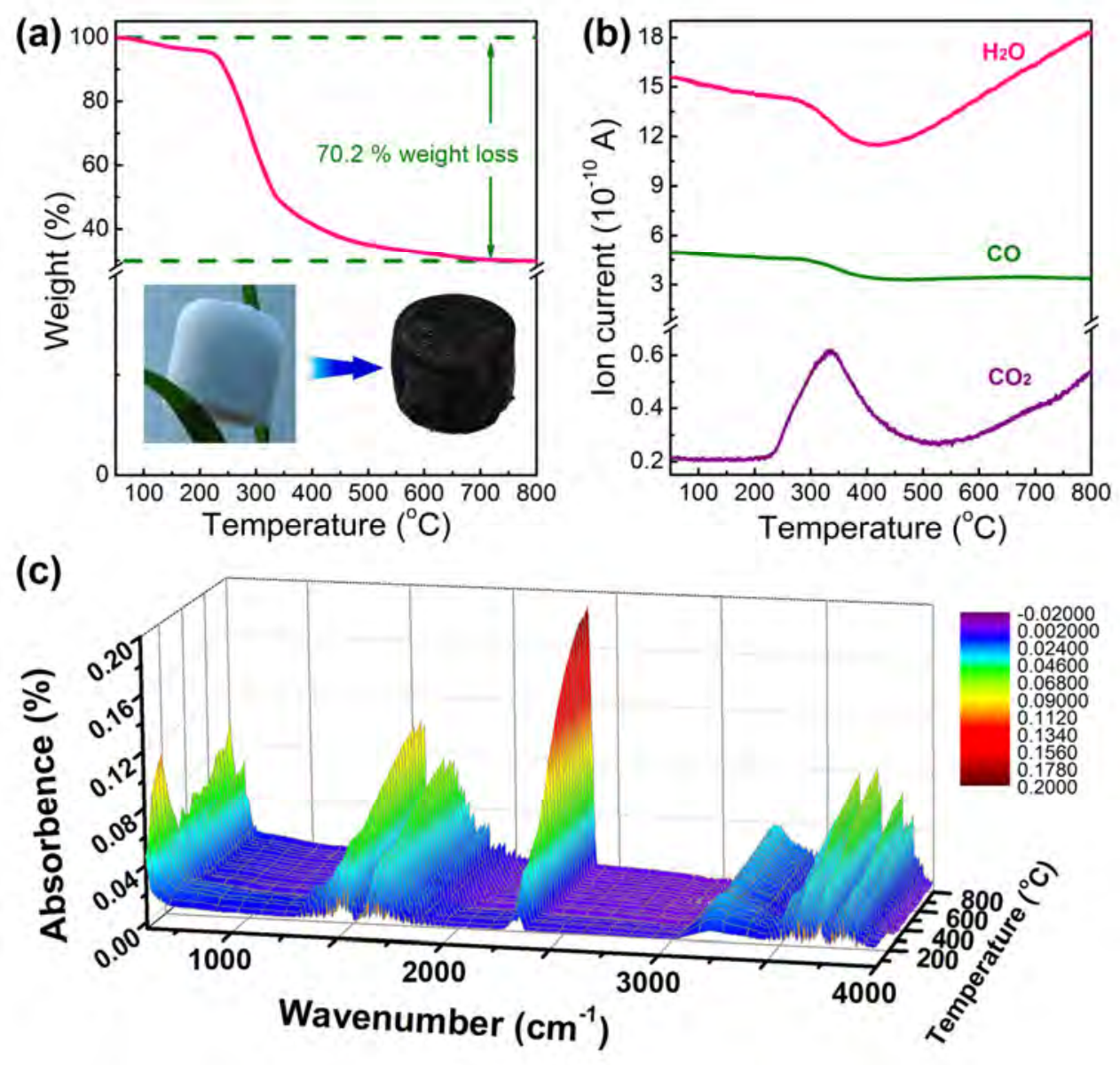

Fig. 3. (a) TGA curve of cellulose nanofiber aerogel in $\mathrm{N}_{2}$ atmosphere ((heating rate of $5{ }^{\circ} \mathrm{C} \mathrm{min}^{-1}$ ). (b) The analysis of the outlet gases from the decomposition of cellulose nanofiber aerogel TG-MS: $\mathrm{H}_{2} \mathrm{O}$ (pink), $\mathrm{CO}$ (olive), and $\mathrm{CO}_{2}$ (purple). (c) 3D spectra of TG-FTIR of cellulose nanofiber aerogel.

To reveal decomposition process of the cellulose nanofiber aerogel, coupled thermogravimetric and mass spectrum (TG-MS) was carried out. The TG curve of the cellulose nanofiber aerogel presents one distinct weight losses at a temperature range of $230-380{ }^{\circ} \mathrm{C}$ (Fig. 3a). Fig. 3b shows the corresponding mass spectra for TG curve, which demonstrates the evolved gases are $\mathrm{H}_{2} \mathrm{O}(\mathrm{m} / \mathrm{z}$ : 18), $\mathrm{CO}(\mathrm{m} / \mathrm{z}: 28)$, and $\mathrm{CO}_{2}(\mathrm{~m} / \mathrm{z}: 44)$. At the all the decomposition process, a mass of $\mathrm{H}_{2} \mathrm{O}, \mathrm{CO}$, and $\mathrm{CO}_{2}$ are evolved from the cellulose macromolecules. A 
obvious peak is observed at $340{ }^{\circ} \mathrm{C}$ from the purple curve $\left(\mathrm{CO}_{2}\right)$, which is ascrbied to the fast decomposition stage at around $230-470{ }^{\circ} \mathrm{C}$ (Fig. 3a), corresponding to the TG curve. Thus, the whole thermal decomposition process of the cellulose nanofiber aerogel is the oxygen-containing groups (such as -C-OC-, and $-\mathrm{OH}$ ) in cellulose macromolecular converted to $\mathrm{H}_{2} \mathrm{O}, \mathrm{CO}$, and $\mathrm{CO}_{2}$. The product of the pyrolysis process is the CNFA with 29.8 wt \% retention. TGFourier transform infrared spectroscopy (TG-FTIR) spectra in the thermal decomposition process of cellulose nanofiber aerogel further gave the evidence for the gas components evolved. As shown in Fig. 3c, the peaks located at 3851$3253 \mathrm{~cm}^{-1}$ and $2360 \mathrm{~cm}^{-1}$ in all the spectra indicate the release of $\mathrm{H}_{2} \mathrm{O}$ vapour and $\mathrm{CO}_{2}$ in the whole pyrolysis process. The two peaks positioned at 1682 and 1541 $\mathrm{cm}^{-1}$ are ascribed to the stretching vibration of $\mathrm{C}=\mathrm{O}$ and $\mathrm{C}=\mathrm{C}$, respectively, which demonstrate the existence of alkane, ketone, or carboxylic acids.
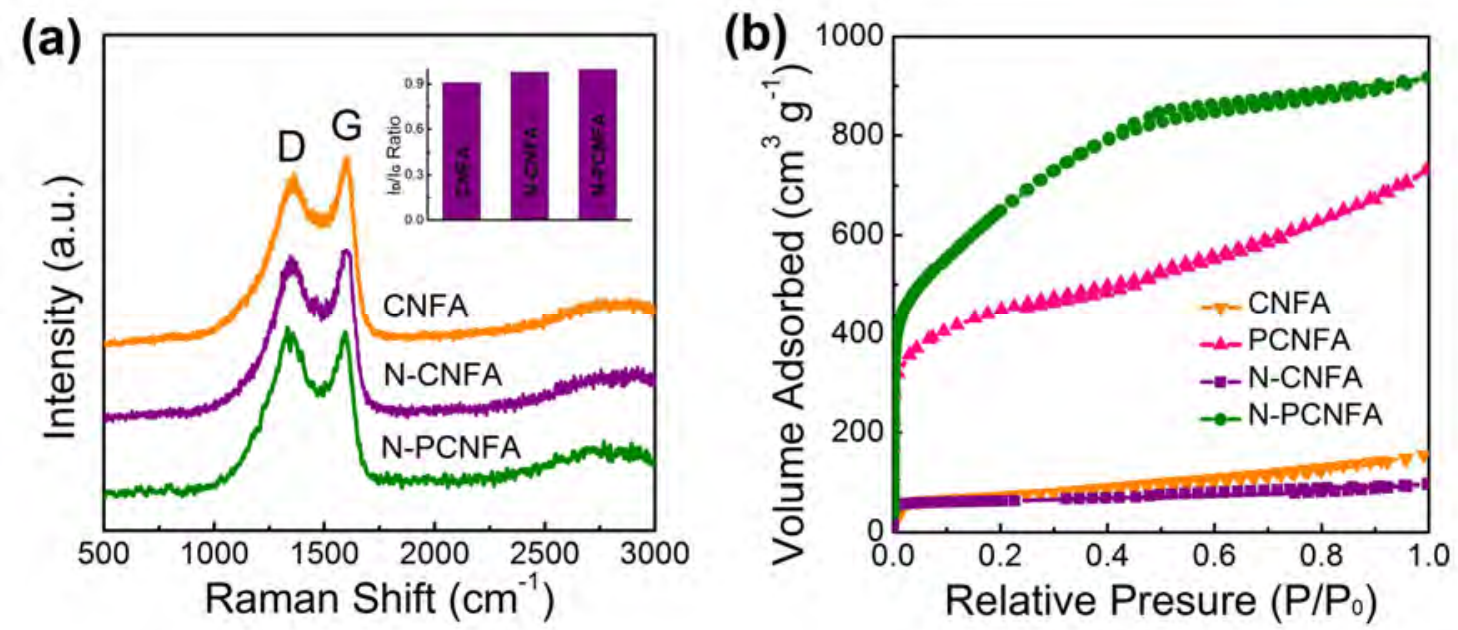

Fig. 4. (a) Raman spectroscopy of CNFA, N-CNFA, and N-PCNFA. (b) Nitrogen adsorption-desorption isotherm for CNFA, PCNFA, N-CNFA, and N-PCNFA. 
The Raman spectra of CNFA, N-CNFA, and N-PCNFA are presented in Fig. 4a. The D-band is attributed to the amorphous carbon or defective graphitic structure, and the G-band is a characteristic feature of graphitic carbon. The intensity of $\mathrm{I}_{\mathrm{D}} / \mathrm{I}_{\mathrm{G}}$ illustrates the disorder degree in the carbon structure $[31,32]$. Compared with the $I_{D} / I_{G}$ of CNFA (0.91) and N-CNFA (0.98), more defects can be generated through the $\mathrm{N}$-doping. The $I_{\mathrm{D}} / I_{\mathrm{G}}$ ratio of $\mathrm{N}-\mathrm{PCNFA}$ (1.01) was higher than of N-CNFA, indicating that the $\mathrm{KOH}$ activation process could generate more defects on the carbon framework. The defects can increase the energy storage sites for LIBs and SCs to enhance the electrochemical performance. The $\mathrm{N}_{2}$ adsorption/desorption analysis was used to measure the specific surface area and pore size distributions of N-PCNFA, N-CNFA, PCNFA, and CNFA. The $\mathrm{N}_{2}$ adsorption/desorption isotherms show that the major absorption of the four samples presents at low relative pressure $\left(\mathrm{P} / \mathrm{P}_{0}<0.02\right)$, which is corresponding to typical type I adsorption isotherm, confirming the adsorption in micropores (Fig. 4b). In addition, the isotherm of N-PCNFA also exhibits a hysteresis loop (typical type IV), arising from the mesoporous structure. The surface areas of N-PCNFA, N-CNFA, PCNFA, and CNFA are 2290, 1536, 199 , and $242 \mathrm{~m}^{2} \mathrm{~g}^{-1}$, respectively, indicating the prominent surface areas of $\mathrm{N}$ PCNFA and PCNFA result from the $\mathrm{KOH}$ activation treatment [33]. The pore size distributions of N-PCNFA and PCNFA calculated from the adsorption branch are mainly centered at between 1.5-4 nm, suggesting the formation of micropores and partly small-sized mesopores through $\mathrm{N}$-doping and $\mathrm{KOH}$ activation (Fig. S3). The high surface area and micro-mesoporous structure can storage the electrolyte and increase the active material/electrolyte interface area 
to promote the transport of ions, thus facilitating the rate performance for LIBs and SCs.

(a)

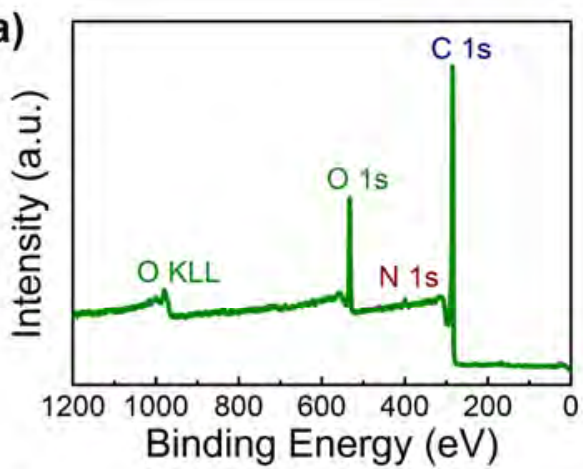

(c)

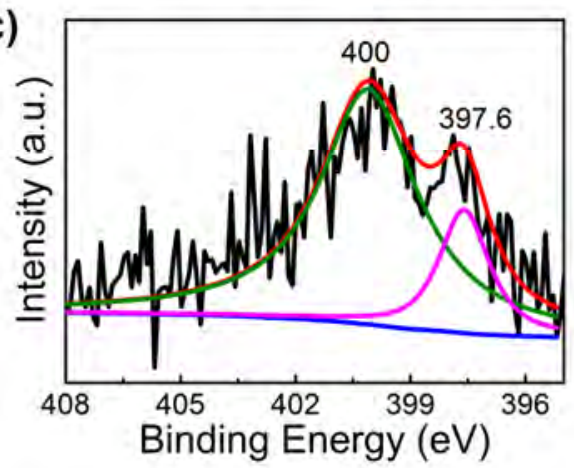

(b)

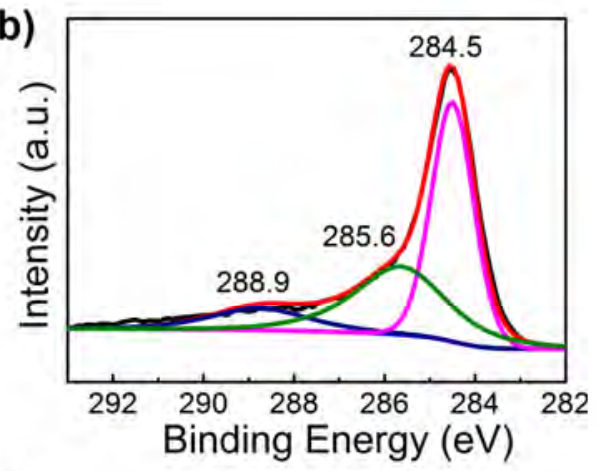

(d)

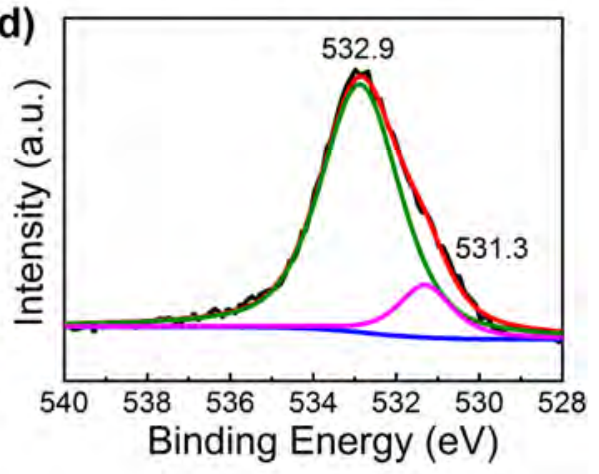

Fig. 5. XPS spectra of N-PCNFA, (a) full survey scan spectrum, (b) C 1s, (c) N 1s, and (d) O 1s spectra.

X-ray photoelectron spectroscopy (XPS) was used to identify the chemical state of elementin N-PCNFA. The full survey spectrum shows three peaks located at about 284, 400, and $533 \mathrm{eV}$, corresponding to the characteristic peaks of $\mathrm{C} 1 \mathrm{~s}$, $\mathrm{N}$ 1s, and $\mathrm{O}$ 1s, respectively (Fig. 5a). XPS spectrum of $\mathrm{N} 1 \mathrm{~s}$ was deconvoluted into two peaks positioned at $397.6 \mathrm{eV}$ (pyridinic-N) and $400 \mathrm{eV}$ (pyrrolic-N) (Fig. 5b) $[34,35]$. Such N-containing structure in the carbon framwork can enhance the electrochemical conductivity of the sample, favouring the binding of electrolyte ions [36]. Fig. 5c shows the C 1s spectrum of the N-PCNFA. Three peaks located at $284.5,285.6$, and $288.9 \mathrm{eV}$ correspond to $\mathrm{C}=\mathrm{C}$ and $\mathrm{C}-\mathrm{C}, \mathrm{C}-\mathrm{O}$, and $\mathrm{O}-\mathrm{C}=\mathrm{O}$, 
respectively. Furthermore, the deconvoluted spectrum for $\mathrm{O} 1 \mathrm{~s}$ with two peaks located at 531.3 and $532.9 \mathrm{eV}$ are assigned to $\mathrm{C}=\mathrm{O}$ and $\mathrm{C}-\mathrm{OH}$ groups, respectively (Fig. 5d). The $\mathrm{C} 1 \mathrm{~s}$ and $\mathrm{O} 1 \mathrm{~s}$ spectra indicate the residual oxygencontaining groups bonded with $\mathrm{C}$ atom in N-PCNFA after the pyrolysis and activation process [37].

\subsection{The electrochemical properties}

(a)

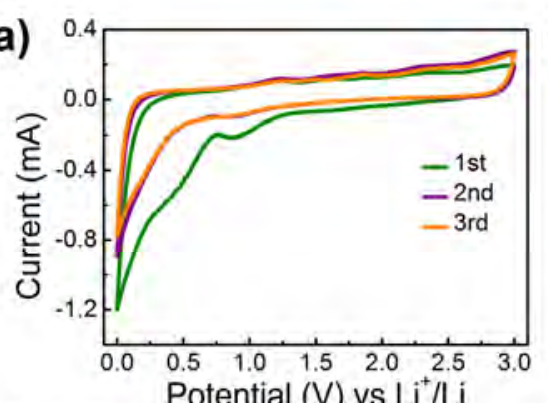

(c)

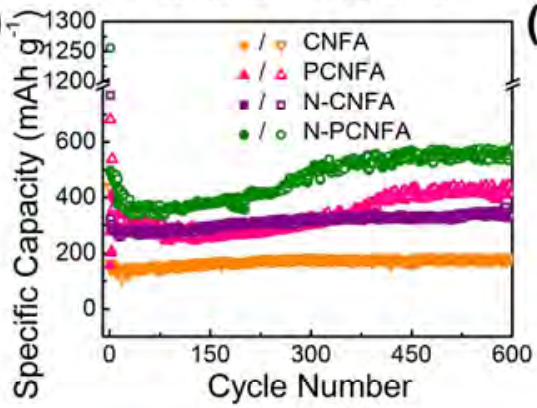

(e)

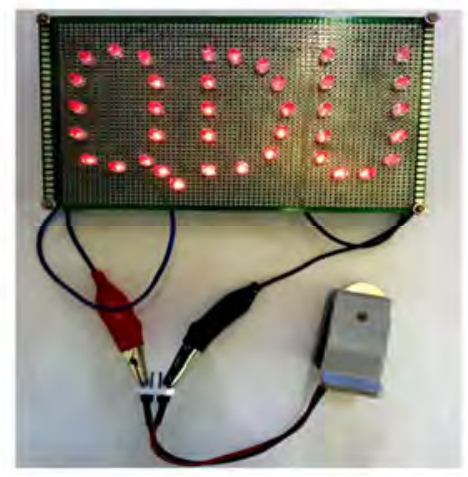

(b)

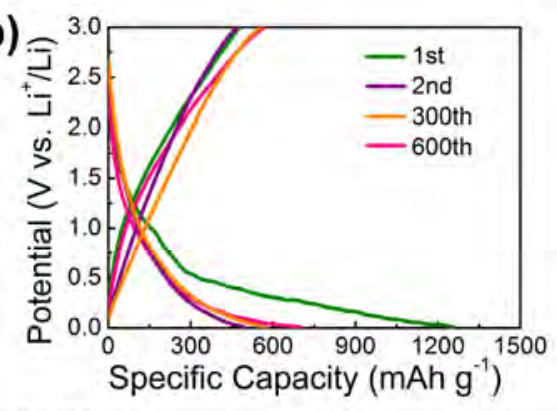

(d) $\div$

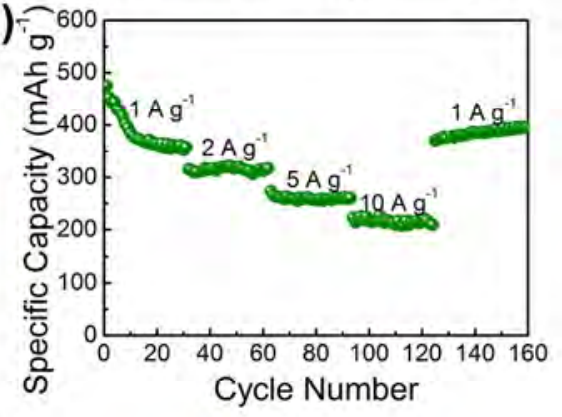

(f)

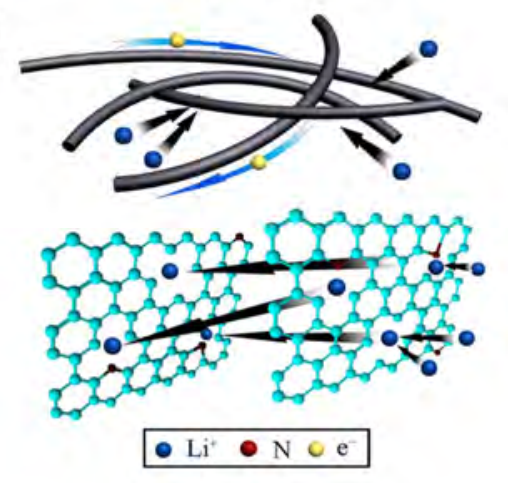

Fig. 6. (a) CV curves of N-PCNFA at different cycles. (b) The galvanostatic charge/discharge curves of N-PCNFA cycled at the $1^{\text {st }}, 2^{\text {nd }}, 300^{\text {th }}$, and $600^{\text {th }}$ between 0.01 and $3.0 \mathrm{~V}\left(v s . \mathrm{Li}^{+} / \mathrm{Li}\right)$ at a current density of $1 \mathrm{~A} \mathrm{~g}^{-1}$. (c) Specific capacity comparisons at different cycles of CNFA, PCNFA, N-CNFA, and N-PCNFA at a current 
density of $1 \mathrm{~A} \mathrm{~g}^{-1}$. (d) The charge specific capacity of the N-PCNFA at different current densities. (e) The optical image of the LEDs lit by one half-cell using N-PCNFA and Li metal foil as electrodes. (f) Schematic illustration of the advantages of N-PCNFA in enhancing lithium storage performance.

The electrochemical properties of the samples as lithium storage materials were examined in a half-cell test by cyclic voltammetry (CV) and galvanostatic cycling techniques. Fig. 6a exhibits the CV curves of N-PCNFA electrode, which show the typical curves of carbon-based materials. For the first cycle, the reduction peaks at 0.53 and $0.87 \mathrm{~V}$ in the cathodic scan are attributed to the formation of solid electrolyte interphase (SEI) layer. Both peaks disappear from the second cycle because that the passivation SEI layer prevents the decomposition of electrolyte. The integrated area intensity in the third cycle is nearly unchanged compared with the second one, suggesting the good cycling stability of the N-PCNFA electrode. The GCD curves of the N-PCNFA at $1 \mathrm{~A} \mathrm{~g}^{-1}\left(v s . \mathrm{Li}^{+} / \mathrm{Li}, 0.01-3.0 \mathrm{~V}\right)$ are shown in Fig. 6b. For the first discharge curve, the discharge plateaus at around 0.9 and $0.5 \mathrm{~V}$ was due to the formation of SEI layer, corresponding to the CV curve of the first cycle. The first charge and discharge specific capacities of N-PCNFA are 480 and $1256 \mathrm{mAh} \mathrm{g}^{-1}$ with a low coulombic efficiency of $38.2 \%$. The specific capacity becomes stable after the first cycle. The NPCNFA exhibits high charge specific capacity and excellent stability $\left(572 \mathrm{mAh} \mathrm{g}^{-1}\right.$ at current densities of $1 \mathrm{~A} \mathrm{~g}^{-1}$ over 600 cycles). Under the identical conditions, the CNFA, PCNFA, and N-CNFA present a charge specific capacity of 182,422 , and $347 \mathrm{mAh} \mathrm{g}^{-1}$ after 600 cycles, respectively (Fig. 6c). The increased capacity of N-PCNFA and PCNFA after cycling should be ascribed to the continuous activation process of the highly porous carbon [35]. The rate performance of N-PCNFA was evaluated at the 
current densities of 1, 2, 5, and $10 \mathrm{~A} \mathrm{~g}^{-1}$ for 30 cycles (Fig. 6d). The N-PCNFA can be reversibly charged to 320,263 and $220 \mathrm{mAh} \mathrm{g}^{-1}$ at the current densities of 2, 5, and 10 $\mathrm{A} \mathrm{g}^{-1}$, respectively. When the current density returned back to $1 \mathrm{~A} \mathrm{~g}^{-1}$ after 120 cycles, the specific capacity can be increased to $380 \mathrm{mAh} \mathrm{g}^{-1}$. As shown in Fig. 6e, the lightemitting diodes (LEDs) were lit by one CR2016-type coin cell using N-PCNFA and Li metal foil as electrodes, implying the N-PCNFA is a high performance lithium storage material.

The unique N-doped hierarchical porous nanofibrous of N-PCNFA showed high capacity, excellent stability and rate performance as lithium storage material. As illustrated in Fig. 6f, the 3D structured CNF aerogel with interconnected hierarchical pores can provide channels for electron transport, which is crucial for promoting the conductivity of the electrode. The $\mathrm{N}$-doping and activation processes can generate more defects in the carbon frameworks, allowing more $\mathrm{Li}^{+}$diffuse into inner carbon to explore more lithium storage sites, and the $\mathrm{N}$-doping can improve electrochemical conductivity to enhance the electron transport, which has been proved by the electrochemical impedance spectroscopy (Fig. S4) [38, 39]. Furthermore, The N atoms doped in the carbon framework are favourable to bind with $\mathrm{Li}^{+}$to enhance the specific capacity and rate performance of the sample [40]. 


\section{(a)}

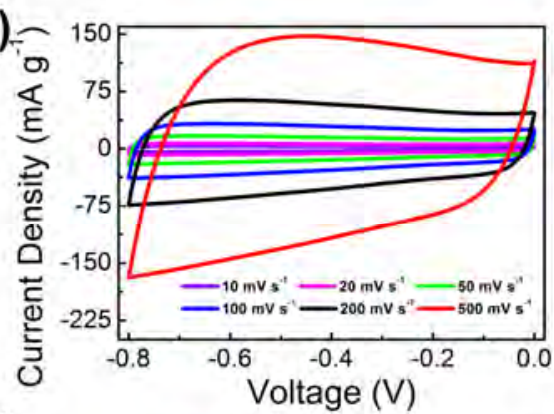

(c)

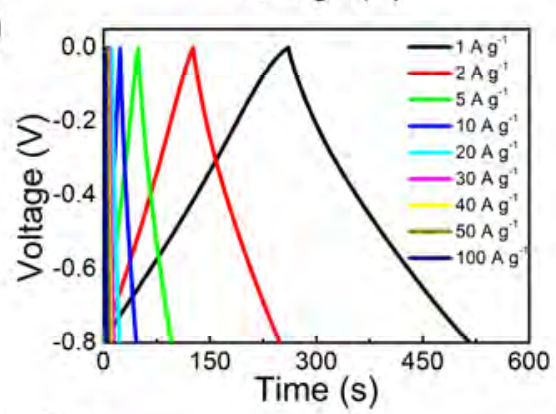

(e)

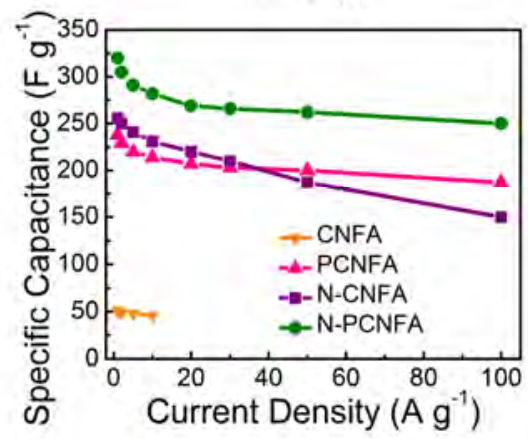

(b)

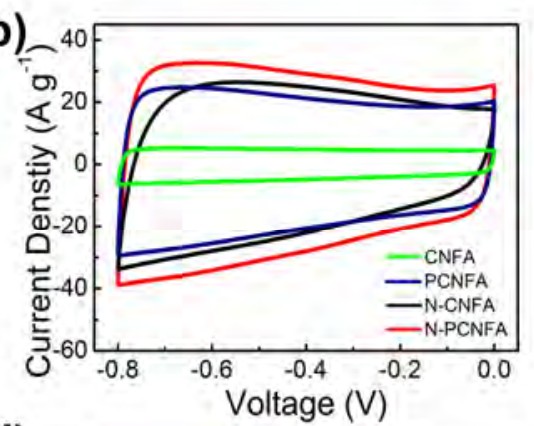

(d)

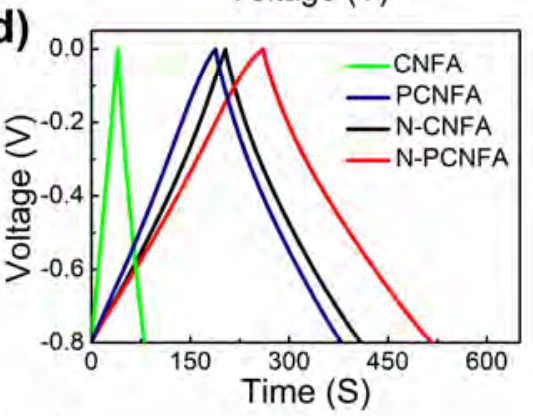

(f)

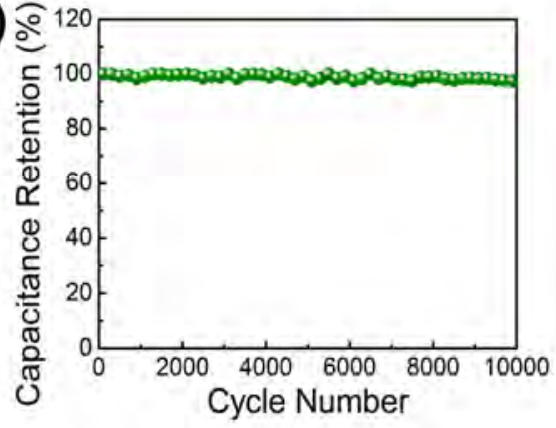

Fig. 7. Electrochemical performance characteristics measured in a three-electrode system. (a) CV curves of N-PCNFA in $6.0 \mathrm{M} \mathrm{KOH}$ solution between -0.8 and $0 \mathrm{~V}$ at different scan rates. (b) CV curves of CNFA, PCNFA, N-CNFA, and N-PCNFA in 6.0 $\mathrm{M} \mathrm{KOH}$ solution at a scan rate of $100 \mathrm{mV} \mathrm{s}^{-1}$. (c) Galvanostatic charge/discharge curves of N-PCNFA at different current densities. (d) Galvanostatic charge/discharge curves of CNFA, PCNFA, N-CNFA, and N-PCNFA at the current density of $1 \mathrm{~A} \mathrm{~g}^{-1}$. (e) The specific capacitances of CNFA, PCNFA, N-CNFA, and N-PCNFA at various current densities. (f) Capacitance retention ratio for N-PCNFA at a current density of $5 \mathrm{Ag}^{-1}$ for 10000 cycles. 
The electrochemical performances of samples for SCs were tested using threeelectrode system (6 M KOH as electrolyte). Especially, we tested the samples directly without addition of binder. Fig. 7a shows the CV curves of the N-PCNFA at different scan ra tes. All of the CV curves display a typical rectangular shape between -0.8 and $0 \mathrm{~V}$. The CV curves of N-CNFA, PCNFA, and CNFA also exhibit rectangular shape (Fig. 7b and S5). Fig. 7c presents the GCD curves of NPCNFA at different current densities with the symmetric curves, indicating the excellent electric double layer capacitive properties. The specific capacitances of N-PCNFA are determined to be $320,291,282,269,262$, and $248 \mathrm{~F} \mathrm{~g}^{-1}$ at the current densities of $1,5,10,20,50$, and $100 \mathrm{~A} \mathrm{~g}^{-1}$, respectively. The specific capacitance of N-PCNFA at high current density of $100 \mathrm{~A} \mathrm{~g}^{-1}$ can still keep about $78.4 \%$ of that value at $1 \mathrm{~A} \mathrm{~g}^{-1}$, highlighting the excellent rate performance of $\mathrm{N}$ PCNFA. Comparing the GCD curves of CNFA, PCNFA, N-CNFA, and NPCNFA at current density of $1 \mathrm{~A} \mathrm{~g}^{-1}$ (Fig. 7d and S6), the discharge time of the N-PCNFA is longer than that of others, indicating the N-PCNFA offers a higher specific capacitance. The rate performances of CNFA, PCNFA, N-CNFA, and NPCNFA are also shown in Fig. 7e. The N-PCNFA has the highest specific capacitances at all the current densities among the samples, illustrating that the $\mathrm{N}$-doping and $\mathrm{KOH}$ activation processes can intensely enhance the electrochemical performance for SCs. Moreover, the PCNFA exhibits better rate performance than that of N-CNFA. In addition, the N-PCNFA suffers from the issue of low volumetric capacitance attributed to the highly porous structure and low density [41], nevertheless, the N-CNFA with low surface area may show higher volumetric capacitance than those of N-PCNFA and PCNFA. The cycling 
stability of N-PCNFA is also excellent and the specific capacitance remains 92.4 $\%$ after 10000 cycles at $10 \mathrm{~A} \mathrm{~g}^{-1}$ (Fig. 7f).
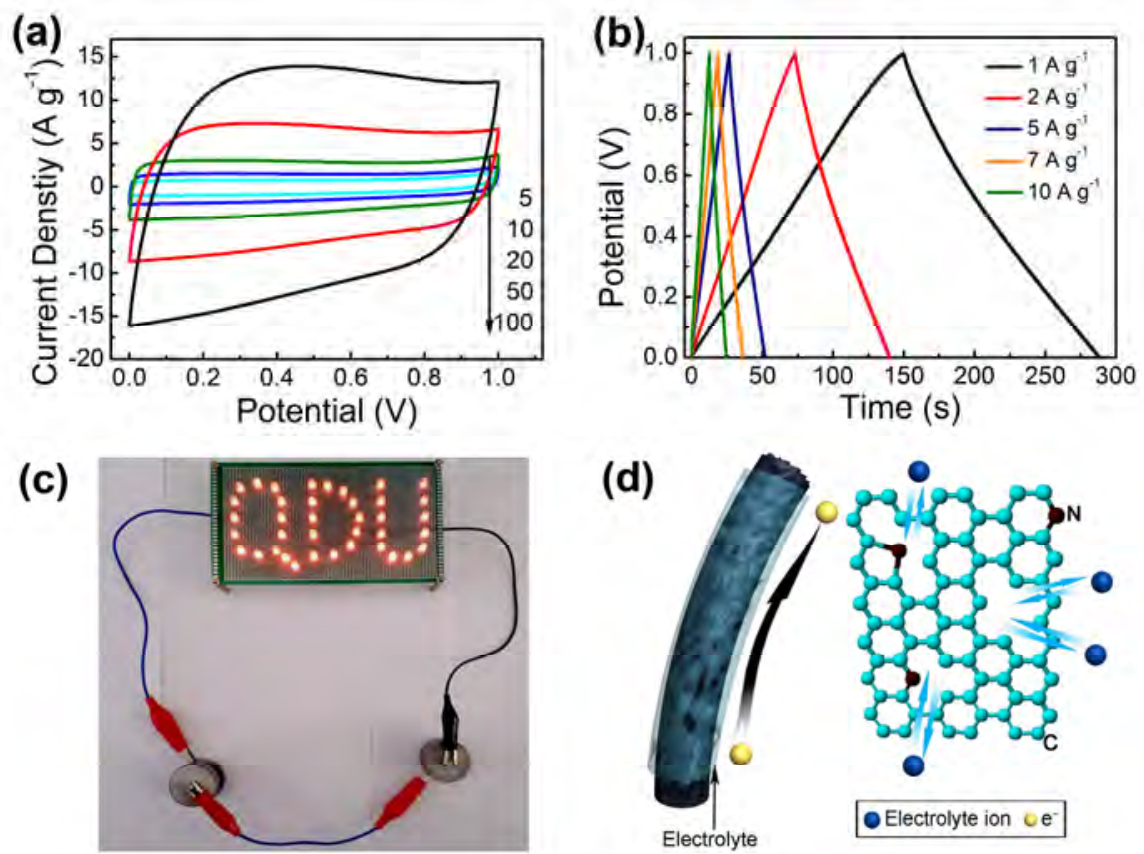

Fig. 8. Electrochemical performance characteristics measured in a two-electrode system. (a) $\mathrm{CV}$ curves of N-PCNFA in $6.0 \mathrm{M} \mathrm{KOH}$ solution between 0 and $1 \mathrm{~V}$ at different scan rates. (b) Galvanostatic charge/discharge curves of N-PCNFA at different current densities. (c) The optical image of the LEDs lit by two SCs in series using NPCNFA as electrodes. (d)Schematic illustration of the advantages of N-PCNFA in enhancing SCs.

We also fabricated a symmetric capacitor with the N-PCNFA as electrodes to evaluate the electrochemical performance in practical SCs application. The $\mathrm{CV}$ curves of $\mathrm{N}$ PCNFA in a two-electrode system also display rectangular shape between 0 and $1.0 \mathrm{~V}$ (Fig. 8a), suggesting in the excellent double-layer capacitive performance. Fig. 8b shows the GCD curves of the two-electrode system with symmetric shape and the specific capacitances are $278,268,251,246$, and $239 \mathrm{~F} \mathrm{~g}^{-1}$ at $1,2,5,7$, and $10 \mathrm{~A} \mathrm{~g}^{-1}$. 
Table 1 summaries the electrochemical performances of carbon materials for supercapacitors, which the N-PCNFA electrode exhibits high capacitance performance. However, the amorphous structured N-PCNFA shows inferior capacitance performance campared the heteroatoms-doped graphene aerogels [42, 43]. The two symmetric SCs using N-PCNFA-based electrodes in series can also light the LEDs (Fig. 8c). As the electrode material for SCs, the specific capacitance and rate performance of N-PCNFA is higher than that of $\mathrm{N}$-free and pore-less samples. As shown in Fig. 8d, the N-doping not only improves electronic conductivity of the sample, but also enhances the charge density of the carbon framwork to promote the adsorption of electrolyte ions and generate pseudocapacity [16]. In addition, the large surface area and micro-mesoporous structure increase the interface between electrolyte and active sites and shorten the diffusion distance of electrolyte ions, thus enhancing the double layer capacitance and rate performance.

Table 1. Comparison of the electrochemical performances of carbon aerogels based two-electrode supercapacitor.

\begin{tabular}{|c|c|c|c|c|}
\hline Carbon material & $\begin{array}{l}\text { BET specific } \\
\text { surface area }\end{array}$ & $\begin{array}{l}\text { Specific capacitance } \\
\qquad\left(\mathrm{F} \mathrm{g} \mathrm{g}^{-\mathbf{1}}\right)\end{array}$ & Electrolyte & Reference \\
\hline Hierarchical porous carbon aerogel & 2200 & $255\left(1.0 \mathrm{~A} \mathrm{~g}^{-1}\right)$ & $6 \mathrm{M} \mathrm{KOH}$ & {$[5]$} \\
\hline $\begin{array}{l}\text { Three-dimensional, } \mathrm{S} \text {-incorporated } \\
\text { graphene aerogel }\end{array}$ & 359.5 & $445.6\left(5.0 \mathrm{mV} \mathrm{S}^{-1}\right)$ & $1 \mathrm{M} \mathrm{H}_{2} \mathrm{SO}_{4}$ & {$[42]$} \\
\hline $\begin{array}{l}\text { P-incorporated graphenes with } \\
\text { hierarchical architecture }\end{array}$ & 383 & $353\left(1.0 \mathrm{~A} \mathrm{~g} \mathrm{~g}^{-1}\right)$ & $1 \mathrm{M} \mathrm{H}_{2} \mathrm{SO}_{4}$ & {$[43]$} \\
\hline N-doped porous carbon/graphene aerogel & 473 & $290\left(1.0 \mathrm{~A} \mathrm{~g}^{-1}\right)$ & $1 \mathrm{M} \mathrm{H}_{2} \mathrm{SO}_{4}$ & {$[44]$} \\
\hline N-doped graphene aerogel & 830 & $223\left(0.2 \mathrm{~A} \mathrm{~g}^{-1}\right)$ & $1 \mathrm{M} \mathrm{H}_{2} \mathrm{SO}_{4}$ & {$[45]$} \\
\hline B/N co-doped porous carbon network & 2666 & $214\left(0.2 \mathrm{~A} \mathrm{~g}^{-1}\right)$ & $6 \mathrm{M} \mathrm{KOH}$ & {$[46]$} \\
\hline Hierarchical carbon foam & 2772 & $240\left(1.0 \mathrm{~A} \mathrm{~g}^{-1}\right)$ & $1 \mathrm{M} \mathrm{H}_{2} \mathrm{SO}_{4}$ & ["47] \\
\hline $\begin{array}{c}\text { Graphene-carbon nanotube foam } \\
\text { architecture }\end{array}$ & 743 & $286\left(1.78 \mathrm{~mA} \mathrm{~cm}^{-2}\right)$ & $6 \mathrm{M} \mathrm{KOH}$ & [48] \\
\hline Graphene oxide sponges & 239.2 & $247.6\left(1.0 \mathrm{~A} \mathrm{~g}^{-1}\right)$ & $1 \mathrm{M} \mathrm{H}_{2} \mathrm{SO}_{4}$ & {$[49]$} \\
\hline Hierarchical porous graphene frameworks & 829 & $278.5\left(5.0 \mathrm{mV} \mathrm{S}^{-1}\right)$ & $1 \mathrm{M} \mathrm{H}_{2} \mathrm{SO}_{4}$ & {$[50]$} \\
\hline N-PCNFA & 2290 & $278\left(1.0 \mathrm{~A} \mathrm{~g}^{-1}\right)$ & $6 \mathrm{M} \mathrm{KOH}$ & "This work \\
\hline
\end{tabular}




\section{Conclusions}

We successfully explored the $\mathrm{N}$-doped porous carbon nanofiber aerogel using the residue of gelidium amansii after extraction of agar as precursor with a large surface area and micro-mesoporous structure as high-performance multifunctional energy storage material. The unique structure of $1 \mathrm{D}, \mathrm{N}$-doping, and porous structure plays a crucial part in promoting the energy sotage performance of the carbon-based materials. Given the utilization of the residue of agar production, this work opens a new way in increasing utilization rate of earthabundant seaweed resource for developing low-cost and large-scale nanostructured carbonaceous energy storage materials via a green pathway and promotes the development of seaweed industry and energy storage material industry.

\section{Acknowledgements}

We are grateful for the financial support by the National Natural Science Foundation of China (grant no. 51473081 and 51672143), Taishan Scholars Program, and Outstanding Youth of Natural Science in Shandong Province (JQ201713), and ARC Discovery Project (No. 170103317).

\section{Appendix A. Supplementary data}

Supplementary data related to this article can be found at https://doi.

\section{References}


[1] F. Béguin, V. Presser, A. Balducci, E. Frackowiak, Carbons and electrolytes for advanced supercapacitors, Adv. Mater. 26 (2014) 2219-2251.

[2] L.-F. Chen, X.-D. Zhang, H.-W. Liang, M. Kong, Q.-F. Guan, P. Chen, Z.-Y. Wu, S.-H. Yu, Synthesis of nitrogen-doped porous carbon nanofibers as an efficient electrode material for supercapacitors, ACS Nano 2 (2012) 70927102.

[3] Y. Chen, X. Li, K. Park, J. Song, J. Hong, L. Zhou, Y.W. Mai, H. Huang, J.B. Goodenough, Hollow carbon-nanotube/carbon-nanofiber hybrid anodes for Liion batteries, J. Am .Chem. Soc. 135 (2013) 16280-16283.

[4] Y. Chen, X. Li, X. Zhou, H. Yao, H. Huang, Y.-W. Mai, L. Zhou, Hollowtunneled graphitic carbon nanofibers through Ni-diffusion-induced graphitization as high-performance anode materials, Energy Environ. Sci. 7 (2014) 2689-2696.

[5] J. Cui, Y. Xi, S. Chen, D. Li, X. She, J. Sun, W. Han, D. Yang, S. Guo, Prolifera-green-tide as sustainable source for carbonaceous aerogels with hierarchical pore to achieve multiple energy storage, Adv. Funct. Mater. 26 (2016) 8487-8495.

[6] L. Dai, D.W. Chang, J.B. Baek, W. Lu, Carbon nanomaterials for advanced energy conversion and storage, Small 8 (2012) 1130-1166.

[7] M.S. Dresselhaus, A. Jorio, M. Hofmann, G. Dresselhaus, R. Saito, Perspectives on carbon nanotubes and graphene Raman spectroscopy, Nano Lett. 10 (2010) 751-758.

[8] J.L. Goldfarb, G. Dou, M. Salari, M.W. Grinstaff, Biomass-based fuels and activated carbon electrode materials: an integrated approach to green energy systems, ACS Sustainable Chem. Eng. 5 (2017) 3046-3054.

[9] K. Gupta, T. Liu, R. Kavian, H.G. Chae, G.H. Ryu, Z. Lee, S.W. Leeb, S. Kumar, High surface area carbon from polyacrylonitrile for high-performance electrochemical capacitive energy storage, J. Mater. Chem. A 4 (2016) 1829418299.

[10] Z. Hu, L. Wang, K. Zhang, J. Wang, F. Cheng, Z. Tao, J. Chen, $\mathrm{MoS}_{2}$ nanoflowers with expanded interlayers as high-performance anodes for sodium-ion batteries, Angew. Chem. Int. Ed. 53 (2014) 12794-12798. 
[11] C. Kim, K.S. Yang, M. Kojima, K. Yoshida, Y.J. Kim, Y.A. Kim, M. Endo, Fabrication of electrospinning-derived carbon nanofiber webs for the anode material of lithium-ion secondary batteries, Adv. Funct. Mater. 16 (2006) 2393-2397.

[12] A.A. Koós, F. Dillon, R.J. Nicholls, L. Bulusheva, N. Grobert, N-SWCNTs production by aerosol-assisted CVD method, Chem. Phys. Lett. 538 (2012) 108-111.

[13] M. Kruk, M. Jaroniec, Gas adsorption characterization of ordered organicinorganic nanocomposite materials, Chem. Mater. 13 (2001) 3169-3183.

[14] B. Li, F. Dai, Q. Xiao, L. Yang, J. Shen, C. Zhang, M. Cai, Activated carbon from biomass transfer for high-energy density lithium-ion supercapacitors, Adv. Energy Mater. 6 (2016) 1600802.

[15] B. Li, F. Dai, Q. Xiao, L. Yang, J. Shen, C. Zhang, M. Cai, Nitrogen-doped activated carbon for a high energy hybrid supercapacitor, Energy Environ. Sci. 9 (2016) 102-106.

[16] D. Li, C. Lv, L. Liu, Y. Xia, X. She, S. Guo, D. Yang, Egg-box structure in cobalt alginate: a new approach to multifunctional hierarchical mesoporous $\mathrm{N}$ doped carbon nanofibers for efficient catalysis and energy storage, ACS Cent. Sci. 1 (2015) 261-269.

[17] D. Li, D. Yang, X. Yang, Y. Wang, Z. Guo, Y. Xia, S. Sun, S. Guo, Doublehelix structure in carrageenan-metal hydrogels: a general approach to porous metal sulfides/carbon aerogels with excellent sodium-ion storage, Angew. Chem. Int. Ed. 55 (2016) 15925-15928.

[18] D. Li, D. Yang, X. Zhu, D. Jing, Y. Xia, Q. Ji, R. Cai, H. Li, Y. Che, Simple pyrolysis of cobalt alginate fibres into $\mathrm{Co}_{3} \mathrm{O}_{4} / \mathrm{C}$ nano/microstructures for a high-performance lithium ion battery anode, J. Mater. Chem. A 2 (2014) $18761-18766$.

[19] Y. Li, Z.-Y. Fu, B.-L. Su, Hierarchically structured porous materials for energy conversion and storage, Adv. Funct. Mater. 22 (2012) 4634-4667.

[20] L. Liu, X. Yang, C. Lv, A. Zhu, X. Zhu, S. Guo, C. Chen, D. Yang, Seaweedderived route to $\mathrm{Fe}_{2} \mathrm{O}_{3}$ hollow nanoparticles/N-doped graphene aerogels with 
high lithium ion storage performance, ACS Appl. Mater. Interfaces 8 (2016) 7047-7053.

[21] L. Liu, X. Yang, N. Ma, H. Liu, Y. Xia, C. Chen, D. Yang, X. Yao, Scalable and cost-effective synthesis of highly efficient $\mathrm{Fe}_{2} \mathrm{~N}$-based oxygen reduction catalyst derived from seaweed biomass, Small 12 (2016) 1295-1301.

[22] Y. Lu, Q. Sun, X. She, Y. Xia, Y. Liu, J. Li, D. Yang, Fabrication and characterisation of alpha-chitin nanofibers and highly transparent chitin films by pulsed ultrasonication, Carbohydr. Polym. 98 (2013) 1497-1504.

[23] Y. Lu, G. Ye, X. She, S. Wang, D. Yang, Y. Yin, Sustainable Route for Molecularly Thin Cellulose Nanoribbons and Derived Nitrogen-Doped Carbon Electrocatalysts, ACS Sustainable Chem. Eng. 5 (2017) 8729-8737.

[24] N. Ma, Y.A. Jia, X. Yang, X. She, L. Zhang, Z. Peng, X. Yao, D. Yang, Seaweed biomass derived $(\mathrm{Ni}, \mathrm{Co}) / \mathrm{CNT}$ nanoaerogels: efficient bifunctional electrocatalysts for oxygen evolution and reduction reactions, J. Mater. Chem. A 4 (2016) 6376-6384.

[25] Q. Ma, Y. Yu, M. Sindoro, A.G. Fane, R. Wang, H. Zhang, Carbon-based functional materials derived from waste for water remediation and energy storage, Adv. Mater. 29 (2017) 1605361.

[26] J.H. Park, J.Y. Hong, H.C. Jang, S.G. Oh, S.H. Kim, J.J. Yoon, Y.J. Kim, Use of Gelidium amansii as a promising resource for bioethanol: a practical approach for continuous dilute-acid hydrolysis and fermentation, Bioresour. Technol. 108 (2012) 83-88.

[27] Y.B. Seo, Y.W. Lee, C.H. Lee, H.C. You, Red algae and their use in papermaking, Bioresor. Technol. 101 (2010) 2549-2553.

[28] J. Sun, C. Lv, F. Lv, S. Chen, D. Li, Z. Guo, W. Han, D. Yang, S. Guo, Tuning the shell number of multishelled metal oxide hollow fibers for optimized lithium-ion storage, ACS Nano 11 (2017) 6186-6193.

[29] T. Tamura, H. Kawakami, Aligned electrospun nanofiber composite membranes for fuel cell electrolytes, Nano Lett. 10 (2010) 1324-1328.

[30] Z. Tan, K. Ni, G. Chen, W. Zeng, Z. Tao, M. Ikram, Q. Zhang, H. Wang, L. Sun, X. Zhu, X. Wu, H. Ji, R.S. Ruoff, Y. Zhu, Incorporating pyrrolic and 
pyridinic nitrogen into a porous carbon made from C60 molecules to obtain superior energy storage, Adv. Mater. 29 (2017) 1603414.

[31] D. Weingarth, M. Zeiger, N. Jäckel, M. Aslan, G. Feng, V. Presser, Graphitization as a universal tool to tailor the potential-dependent capacitance of carbon supercapacitors, Adv. Energy Mater. 4 (2014) 1400316.

[32] K.N. Wood, R. O'Hayre, S. Pylypenko, Recent progress on nitrogen/carbon structures designed for use in energy and sustainability applications, Energy Environ. Sci. 7 (2014) 1212-1249.

[33] Z.-S. Wu, W. Ren, L. Xu, F. Li, H.-M. Cheng, Doped graphene sheets as anode materials with superhigh rate and large capacity for lithium ion batteries ACS Nano 5 (2011) 5463-5471.

[34] J. Xu, F. Xu, M. Qian, F. Xu, Z. Hong, F. Huang, Conductive carbon nitride for excellent energy storage, Adv. Mater. 29 (2017) 1701674.

[35] G. Ye, X. Zhu, S. Chen, D. Li, Y. Yin, Y. Lu, S. Komarnenid, D. Yang, Nanoscale engineering of nitrogen-doped carbon nanofiber aerogels for enhanced lithium ion storage, J. Mater. Chem. A 5 (2017) 8247-8254.

[36] S.B. Yoon, G.S. Chai, S.K. Kang, J.-S. Yu, K.P. Gierszal, M. Jaroniec, Graphitized pitch-based carbons with ordered nanopores synthesized by using colloidal crystals as templates, J. Am. Chem. Soc. 127 (2005) 4188-4189.

[37] M. Yu, Y. Zhang, Y. Zeng, M.S. Balogun, K. Mai, Z. Zhang, X. Lu, Y. Tong, Water surface assisted synthesis of large-scale carbon nanotube film for highperformance and stretchable supercapacitors, Adv. Mater. 26 (2014) 47244729.

[38] B. Zhang, F. Kang, J.-M. Tarascon, J.-K. Kim, Recent advances in electrospun carbon nanofibers and their application in electrochemical energy storage, Prog. Mater. Sci. 76 (2016) 319-380.

[39] W. Zhao, P. Yuan, X. She, Y. Xia, S. Komarneni, K. Xi, Y. Che, X. Yao, D. Yang, Sustainable seaweed-based one-dimensional (1D) nanofibers as highperformance electrocatalysts for fuel cells, J. Mater. Chem. A 3 (2015) 1418814194. 
[40] Y. Zou, S. Chen, X. Yang, N. Ma, Y. Xia, D. Yang, S. Guo, Suppressing Fe-Li antisite defects in $\mathrm{LiFePO}_{4} /$ carbon hybrid microtube to enhance the lithium ion storage, Adv. Energy Mater. 6 (2016) 1601549.

[41] J.Y. Hong, J.J. Wie, Y. Xu, H.S. Park, Chemical modification of graphene aerogels for electrochemical capacitor applications, Phys. Chem. Chem. Phys. 17 (2015) 30946-30962.

[42] X. Yu, S.K. Park, S.H. Yeon, H.S. Park, Three-dimensional, sulfurincorporated graphene aerogels for the enhanced performances of pseudocapacitive electrodes, J. Power Sources 278 (2017) 484-489.

[43] X. Yu, H.J. Kim, J.Y. Hong, Y.M. Jung, K.D. Kwon, J. Kong, H.S. Park, Elucidating surface redox charge storage of phosphorus-incorporated graphenes with hierarchical architectures, Nano Energy 15 (2015) 576-586.

[44] C. Wang, Y. Huang, H. Pan, J. Jiang, X. Yang, Z. Xu, H. Tian, S. Han, D. Wu, Nitrogen-Doped Porous Carbon/Graphene Aerogel with Much Enhanced Capacitive Behaviors, Electrochim. Acta (215) 2016 100-107.

[45] Z.Y. Sui, Y.N. Meng, P.W. Xiao, Z.Q. Zhao, Z.X. Wei, B.H. Han, NitrogenDoped Graphene Aerogels as Efficient Supercapacitor Electrodes and Gas Adsorbents, ACS Appl. Mater. Interfaces (7) 2015 1431-1438.

[46] B. You, F. Kang, P.Q. Yin, Q. Zhang, Hydrogel-derived heteroatom-doped porous carbon networks for supercapacitor and electrocatalytic oxygen reduction, Carbon (103) 2016 9-15.

[47] M. Oschatz, L. Borchardt, K. Pinkert, S. Thieme, M. R. Lohe, C. Hoffmann, M. Benusch, F. M. Wisser, C. Ziegler, Hierarchical Carbide-Derived Carbon Foams with Advanced Mesostructure as a Versatile Electrochemical EnergyStorage Material, Adv. Energy Mater. (4) 20141300645.

[48] W. Wang, S. Guo, M. Penchev, I. Ruiz, K. N. Bozhilov, D. Yan, M. Ozkan, C. S. Ozkan, Three dimensional few layer graphene and carbon nanotube foam architectures for high fidelity supercapacitors, Nano Energy (2) 2013 294-303.

[49] J.Y. Hong, X. Yu, B.M. Bak, C. Pang, H.S. Park, Bio-inspired functionalization and redox charge transfer of graphene oxide sponges for pseudocapacitive electrodes, Carbon (83) 2015 71-78. 
[50] S. Yun, S.O. Kang, S. Park, H.S. Park, $\mathrm{CO}_{2}$-activated, hierarchical trimodal porous graphene frameworks for ultrahigh and ultrafast capacitive behavior, Nanoscale (6) 2014 5296-5302. 


\section{Accepted Manuscript}

Turning gelidium amansii residue into nitrogen-doped carbon nanofiber aerogel for enhanced multiple energy storage

Daohao Li, Yu Wang, Yuanyuan Sun, Yun Lu, Shuai Chen, Bingbing Wang, Huawei Zhang, Yanzhi Xia, Dongjiang Yang

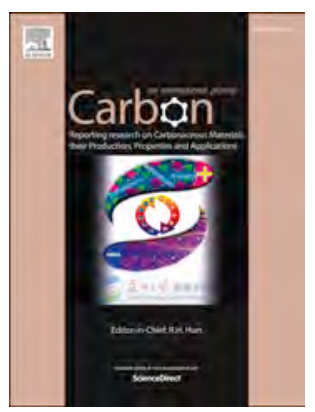

PII:

S0008-6223(18)30471-8

DOI:

10.1016/j.carbon.2018.05.011

Reference: CARBON 13137

To appear in: Carbon

Received Date: 9 February 2018

Revised Date: 8 April 2018

Accepted Date: 4 May 2018

Please cite this article as: D. Li, Y. Wang, Y. Sun, Y. Lu, S. Chen, B. Wang, H. Zhang, Y. Xia, D. Yang, Turning gelidium amansii residue into nitrogen-doped carbon nanofiber aerogel for enhanced multiple energy storage, Carbon (2018), doi: 10.1016/j.carbon.2018.05.011.

This is a PDF file of an unedited manuscript that has been accepted for publication. As a service to our customers we are providing this early version of the manuscript. The manuscript will undergo copyediting, typesetting, and review of the resulting proof before it is published in its final form. Please note that during the production process errors may be discovered which could affect the content, and all legal disclaimers that apply to the journal pertain. 